\title{
Effect of the Ilizarov Bone Fixation on Gait Cycle and Its Parameters
}

\author{
https://doi.org/10.3991/ijoe.v16i11.16155 \\ Omyia Mahmoud Jawad ${ }^{(\bowtie)}$ \\ Al-Nahrain University, Diyala, Iraq \\ omgh 444 egmail. com \\ Sadiq Jaffar Hamandi \\ Al-Nahrain University, Baghdad, Iraq \\ Safa Kadiam Al-Hussainy \\ Baghdad Medical City, Baghdad, Iraq
}

\begin{abstract}
This Walking is the first manner of displacement for human and essential for daily life activities. The human gait can be analyzed from several points of view and specialization. The Ilizarov frame is an external fixation device, primarily used for the treatment of complex fractures which adversely affects the functional state of the locomotor system. The objective of this paper was to analyses the spatiotemporal parameters of gait during treatment by the Ilizarov technique. Materials and methods: The study consists of 6 males with lower limb injuries performed walking trials, with and without the Ilizarov frame. Gait analysis was carried out using a camera and Kinovea application. Results: walking speed $(p=0.385)$, stride length $(p=0.325)$, cadence $(p=0.641)$, stance time of operated limb $(\mathrm{p}=0.265)$, swing time of operated limb ( $\mathrm{p}=0.959)$, double support time of operated limb $(\mathrm{p}=0.227)$ respectively were all no important difference with Ilizarov and without it. The times (stance, swing, and double support) $(\mathrm{p}=0.018)$ for non-operated limb have significantly different with Ilizarov.
\end{abstract}

Keywords - Ilizarov external, spatiotemporal parameters, gait analysis, operated limb, non-operated limb.

\section{$1 \quad$ Introduction}

Human walking is a much complex biomechanical process. A large number of searches have been carried out in the field of human walking[1, 2]. In the medical domain, the knowledgeable of human gait characteristics, the observation and estimating of spatial and temporal parameters of gait, and their changes provide useful therapeutic information for various musculoskeletal diseases [3]. Spatio-temporal parameters are also renowned as general gait parameters. They are answerable for providing the simplest way of objective gait valuation (gait specifications). The gait analysis method considers time-distance parameters such as step and stride length, step width, cadence, velocity, phases (stance and swing), and foot strike and toe-off events for spatiotemporal. 
The stride length is the most remarkable and advantageous gait parameter for both the medical and computing fields [4]. The gait cycle or stride is predominately defined as the interval between initial contact of one foot with the ground and subsequently contact of the same foot. The gait cycle consists of two main phases: the stance phase and the swing phase. The stance phase is that part of the gait cycle when the foot is in contact with the ground, and usually represents about $62 \%$ of the total healthy adult walking gait cycle. The swing phase is defined as the interval when the foot no longer contacts the ground and the limb advances in making ready for subsequent foot contact. The swing phase occupies the residual $38 \%$ of the gait cycle [5]. The stance phase is furthermore divided into an initial double stance, followed by a period of single stance and then a final period of double stance. During a double stance, the weight is transport from one foot to the other. Through a single stance, the center of mass of the body passes above the foot in preparation for shifting to the other limb [6,7]. The cycle time is the interval of a complete gait cycle, which is divided into stance time and swing time[8].

Gait analysis can be described as a domain of biomechanical engineering dealing with the subject of human motion. Via means of various measuring techniques obtainable (for example video registration), human gait data are captured, furthermore, analysis and computations are applied to obtain all the necessary data for valuing the quality of the subject's gait, involving basic gait parameters (stride length, cadence, velocity) [9-11].

In the past, patients with fractures that be unsuccessful in curing (non-union) or healed incorrectly (mal-union) had a few treatments available to them. The patients who required surgical removal of infected bone (osteomyelitis) or cancerous bone had no choice but to have an amputation of the operated limb. The treating of such orthopedic conditions was revolutionized by Dr. Gavril Ilizarov, the Ilizarov frame takes its name from Dr. Gavril Abramovich Ilizarov [12]. The Ilizarov framework consists of individual elements that can be assembled into an unrestrained number of configurations. The adjustability of the apparatus permits the domination of bone angulation, rotation, translation, and lengthening or compression at one or further levels of a bone, either simultaneously or consecutively [13]. The Ilizarov external fixator provides good stabilization of the elongated segment of the locomotor system [14, 15]. During Ilizarov treatment, patients have to learn and adopt correct movement patterns, which requires a very long time since locomotor automatism is established after many repetitions of the correct movements[16, 17]. This study aims to state the effect of Ilizarov on general gait parameters.

\section{$2 \quad$ Patients and Methodology}

\subsection{Patients}

The research group consisted of 8 patients, of whom 6 males were undergone final analysis, treated by the Ilizarov method due to different injuries in the lower limb caused by accident war, as shown in table.1. Most of the patients had subject surgeries 
with other techniques before Ilizarov's operation, but without improvement. Therefore, the Ilizarov method was used for treating them.

Table 1. Characteristic of patient participation

\begin{tabular}{|c|l|c|l|}
\hline Patient No. & sex & age & \multicolumn{1}{|c|}{ Type of injury (Etiology) } \\
\hline 1 & male & 32 & 6-cm long bone loss in the mid-diaphyseal (tibial bone loss)/ Post-traumatic \\
\hline 2 & male & 27 & $\begin{array}{l}\text { fracture of the bottom of the leg bone resulting in severe pain and limited } \\
\text { ankle movement. }\end{array}$ \\
\hline 3 & male & 28 & multiple fractures (above ankle and in femur bone) \\
\hline 4 & male & 24 & mid-diaphyseal of tibia fracture \\
\hline 5 & male & 50 & Deformity of shank bone \\
\hline 6 & male & 33 & Deformity of shank bone \\
\hline
\end{tabular}

\subsection{Methods}

Parameters used in gait analysis and related to time and space are known as temporal and spatial parameters, respectively. These parameters include cadence (stride frequency), stride length, and walking speed. There are several techniques used to measure gait parameters. The procedure is shown below permits each of the three general gait parameters to be measure simultaneously via monitoring the registered gait of the patients by video. The patient completed two test conditions (without Ilizarov (WOI) and with Ilizarov (WI)) at a self-selected, comfortable walking speed bypassing two landmarks in the recording whose positions are known. Spaces before the first mark and after the second marker are essential for acceleration and slowing down during normal walking. When the recording is completed, the period taken to cover the distance between markers is measured, and the number of steps taken is counted. Both of the distance and the time mention previously were measure by utilizing the Kinovea application, as seen in Fig.1. Finally, the time, the distance and the number of steps are all known; general gait parameters may be calculated by use of the following formula [8]:

Cadence $($ steps $/ \mathrm{min})=$ steps counted $\mathrm{x}(60 /$ time $(\mathrm{s}))$

Stride length $(\mathrm{m})=$ distance $(\mathrm{m}) \times(2 /$ steps counted $)$

Speed $(\mathrm{m} / \mathrm{s})=\operatorname{distance}(\mathrm{m}) /$ time $(\mathrm{s})$ 


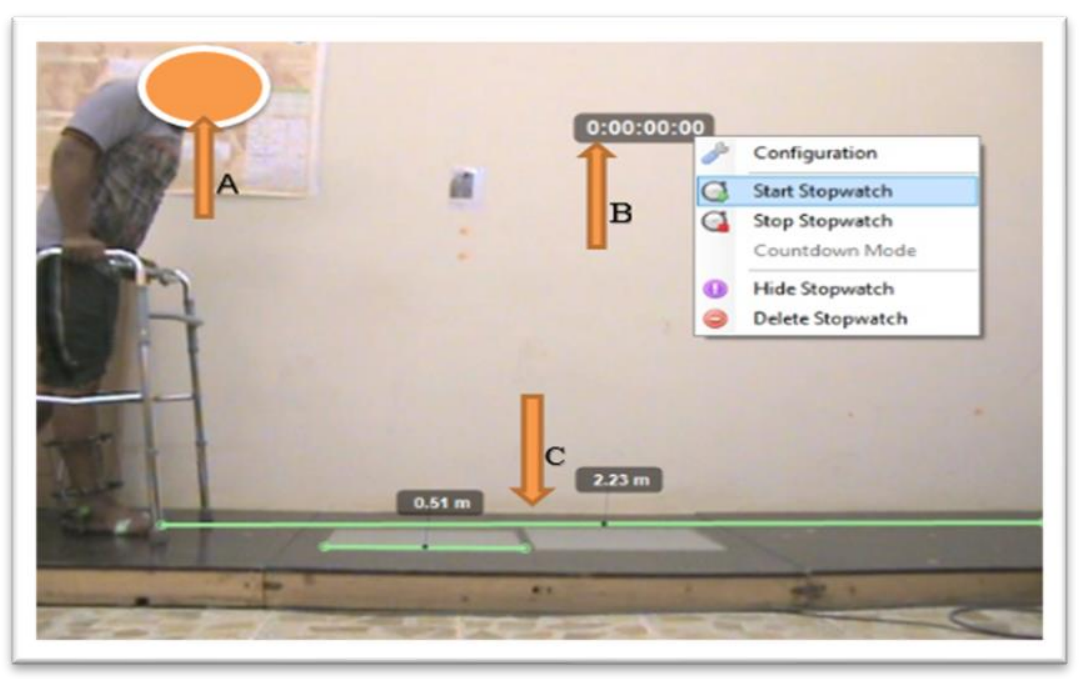

Fig.1. Kenova application. $\mathrm{A}=$ the patient, $\mathrm{B}=$ account the time, $\mathrm{C}=$ the distance of walking.

The stance and swing times for each participant subject were measured manually from the video recording by counting the frames in which the stance and swing take place and then dividing them by the camera's frame rate ( 25 frames/sec). Also knowing the stance and swing duration, the double support can be calculated via utilize of the following formula[18]:

Total double support time $(\mathrm{DS})=$ Stance - Swing

\section{Statistical Analysis}

Statistical analysis was implemented using the IBM SPSS (Statistical Packages for Social Sciences) software version 21.0. Walking speed, cadence, stride length, stance time, swing time, and double support duration data sets were found to be normally distributed through Shapiro-Wilk and Kolmogorov-Smirnov tests $(\mathrm{P} \leq 0.05)$. Descriptive statistics were completed for data sets (means and SDs). Paired- samples T-test used to compare mean values of the variable "difference between without Ilizarov (WOI) and with Ilizarov (WI)". Each analysis was carried out at the level of importance set at a pvalue $<0.05$ was considered as significant discrimination point.

\section{$4 \quad$ Results}

From table.2: mean walking speed, cadence and stride length were higher and not significantly different for WOI compared to WI, where (WOI $=0.303 \mathrm{~ms}^{-1}$ (SD 0.114); $\left.\mathrm{WI}=0.258 \mathrm{~ms}^{-1} \quad(\mathrm{SD} 0.183)\right), \quad\left(\mathrm{WOI}=52.828 \mathrm{steps}^{-\mathrm{min}^{-1}(\mathrm{SD}} 11.353\right) ; \mathrm{WI}=50.104$ steps. $\left.\mathrm{min}^{-1}(\mathrm{SD} 16.869)\right)$, and $(\mathrm{WOI}=0.636 \mathrm{~m}(\mathrm{SD} 0.291) ; \mathrm{WI}=0.583 \mathrm{~m}(\mathrm{SD} 0.258))(\mathrm{P} \geq$ 
$0.05)$ respectively. The mean stance and swing times of operated limb increased when patient wearing Ilizarov frame (WIO=53.963 (SD 28.631); WI=70.301 (SD 8.767)) and (WOI=29.371 (SD 18.108); WI=29.698 (SD 8.767)), but differences between WOI and WI were no statistically significant $(\mathrm{P} \geq 0.05)$ (table.3). The mean stance time of nonoperated limb increased when the patient wearing the Ilizarov frame (WOI=73.877 (SD 9.789); WI=78.161 (SD 11.417)), and there was statistically significant between WOI and WI $(\mathrm{p} \leq 0.05)$ (table.3). While the mean swing time of non-operated limb decreased when the patient wearing the Ilizarov frame (WOI=26.123 (SD 9.789); WI=21.839 (SD $11.417)$ ), and also there was statistically significant between WOI and WI $(p \leq 0.05)$ (table.3). The mean double support duration of operated limb and non-operated limb increased when patient wearing Ilizarov frame (WOI=24.59 (SD 25.072); WI=40.603 $(\mathrm{SD} 17.534)$ ) and (WOI=47.733 (SD 19.577); WI=56.323 (SD 22.833)); but there was not statistically significant between WOI and WI for operated limb $(\mathrm{P} \geq 0.05)$, either non-operated limb has statistically significant between WOI and WI $(\mathrm{p} \leq 0.05)$ (table.4).

\section{Discussion}

This study was focus on comparing significant differences for temporospatial variables between wearing the Ilizarov frame and without. The walking speed of WI $(0.258$ $\left.\mathrm{ms}^{-1}\right)$ was slower than walking speed of WOI $\left(0.303 \mathrm{~ms}^{-1}\right)$ and no significant difference between them. Layton R. B.et al found the walking speed for healthy subjects was decreased with the Ilizarov apparatus also, but they found a significant difference between with and without Ilizarov[19]. In our study, the absence of an important difference for walking speed can be attributed to the deformity of the lower limb for patients. The patients needed more time for walking when wearing the apparatus; therefore, the cadence of WOI (52.828 steps. $\mathrm{min}^{-1}$ ) was higher and not significantly different compared to the cadence of WI (50.104 steps. $\left.\mathrm{min}^{-1}\right)$. The presented study revealed that stride length no significant differences between test conditions. Also, Layton R. B.et al found no significant difference between with and without Ilizarov[19]. Several reports in the past have shown a significantly reduced stride length when treated with an external fixator [20], increased asymmetry between limbs when wearing a unilateral ankle weight [21], and an increased risk of tripping when stepping over obstacles while wearing heavy-duty boots [22]. The study shows that the stance and swing times on operated limbs were longer WI compared to WOI, and no significant difference between them. The stance time on the non-operated limb is increased and considerable difference with Ilizarov, but the swing time on the non-operated limb is a deceased and significant difference with Ilizarov. From mean values in a table.3, it is observed for both tests (WOI and WI) that stance time on the operated limb was shorter than stance time on the nonoperated limb, while swing time on the operated limb was longer than swing time on the non-operated limb. This means the patients depend (leaning) on a non-operated limb more than operated limb to compensate asymmetry of gait. Previous literature identified the stance phase in the operated on the limb was shorter than in the non-operated on the limb, whilst the swing phase in the operated on the limb was longer than in the nonoperated on the limb in children with leg length discrepancy [23, 24]. Also, the study 
demonstrated that the double support duration of the operated limb with Ilizarov was higher and no significant difference compared to without Ilizarov, whilst the double support duration of the non-operated limb with Ilizarov was a higher and significant difference compared to without Ilizarov. i.e., the Ilizarov device effects on non-operated to support and stabilize the lower limb during gait.

Table 2. Statistical analysis of gait parameters

\begin{tabular}{|c|l|c|c|c|}
\hline \multicolumn{1}{|c|}{ Gait parameters } & Lower extremity & Mean \pm SD & t & p \\
\hline \multirow{2}{*}{ Walking speed (m/s) } & Without Ilizarov & $0.303 \pm 0.114$ & 0.952 & \multirow{2}{*}{0.385} \\
\cline { 2 - 3 } & With Ilizarrov & $0.258 \pm 0.183$ & & \\
\hline \multirow{2}{*}{ Cadence (steps/min) } & Without Ilizarov & $52.828 \pm 11.353$ & 0.495 & 0.641 \\
\cline { 2 - 3 } & With Ilizarov & $50.104 \pm 16.869$ & & \\
\hline Stride length (m) & Without Ilizarov & $0.636 \pm 0.291$ & \multirow{2}{*}{1.09} & \multirow{2}{*}{0.325} \\
\cline { 2 - 3 } & With Ilizarrov & $0.583 \pm 0.258$ & & \\
\hline
\end{tabular}

Table 3. Statistical analysis of stance and swing phase expressed as a percentage of the total gait

\begin{tabular}{|c|c|c|c|c|c|c|c|c|}
\hline & \begin{tabular}{|c|} 
Operated \\
Limb
\end{tabular} & Mean \pm SD & $\mathbf{t}$ & $\mathbf{p}$ & \begin{tabular}{|c|} 
Non-operated \\
limb
\end{tabular} & Mean \pm SD & $\mathbf{t}$ & p \\
\hline \multirow[t]{2}{*}{$\begin{array}{l}\% \text { Stance } \\
\text { time }\end{array}$} & $\begin{array}{l}\text { Without } \\
\text { Ilizarov }\end{array}$ & $\begin{array}{c}53.963 \pm \\
28.631\end{array}$ & \multirow[t]{2}{*}{-1.255} & \multirow[t]{2}{*}{0.265} & $\begin{array}{l}\text { Without Iliza- } \\
\text { rov }\end{array}$ & $73.877 \pm 9.789$ & \multirow[t]{2}{*}{-3.454} & \multirow[t]{2}{*}{0.018} \\
\hline & $\begin{array}{l}\text { With Iliza- } \\
\text { rov }\end{array}$ & $\begin{array}{c}70.301 \pm \\
8.767\end{array}$ & & & With Ilizarov & $78.161 \pm 11.417$ & & \\
\hline \multirow[t]{2}{*}{$\begin{array}{l}\% \text { Swing } \\
\text { time }\end{array}$} & $\begin{array}{l}\text { Without } \\
\text { Ilizarov }\end{array}$ & $\begin{array}{c}29.371 \pm \\
18.108\end{array}$ & \multirow[t]{2}{*}{-0.054} & \multirow[t]{2}{*}{0.959} & $\begin{array}{l}\text { Without Iliza- } \\
\text { rov }\end{array}$ & $26.123 \pm 9.789$ & \multirow[t]{2}{*}{3.455} & \multirow[t]{2}{*}{0.018} \\
\hline & $\begin{array}{l}\text { With Iliza- } \\
\text { rov }\end{array}$ & $\begin{array}{c}29.698 \pm \\
8.767\end{array}$ & & & With Ilizarov & $21.839 \pm 11.417$ & & \\
\hline
\end{tabular}

Table 4. Statistical analysis of double support duration expressed as a percentage of the total gait

\begin{tabular}{|c|c|c|c|c|c|c|c|c|}
\hline & $\begin{array}{c}\text { Operated } \\
\text { Limb }\end{array}$ & Mean \pm SD & $\mathbf{t}$ & $\mathbf{p}$ & $\begin{array}{l}\text { Non-oper- } \\
\text { ated limb }\end{array}$ & Mean \pm SD & $\mathbf{t}$ & $\mathbf{p}$ \\
\hline \multirow{2}{*}{$\begin{array}{l}\text { \%Double } \\
\text { support } \\
\text { duration }\end{array}$} & $\begin{array}{l}\text { Without } \\
\text { Ilizarov }\end{array}$ & $\begin{array}{l}24.59 \pm \\
25.072\end{array}$ & \multirow[t]{2}{*}{-1.377} & \multirow[t]{2}{*}{0.227} & $\begin{array}{l}\text { Without } \\
\text { Ilizarov }\end{array}$ & $\begin{array}{c}47.733 \\
\pm 19.577 \\
\end{array}$ & \multirow[t]{2}{*}{-3.456} & \multirow[t]{2}{*}{0.018} \\
\hline & $\begin{array}{l}\text { With } \\
\text { Ilizarrov }\end{array}$ & $\begin{array}{c}40.603 \\
\pm 17.534\end{array}$ & & & $\begin{array}{l}\text { With } \\
\text { Ilizarrov }\end{array}$ & $\begin{array}{c}56.323 \\
\pm 22.833\end{array}$ & & \\
\hline
\end{tabular}

\section{Conclusion}

This review identified that the presence or absence of the Ilizarov device does not significantly affect on gait parameters (speed, cadence, and stride length), and times (stance, swing and double support) for operated limb. Whereas the Ilizarov influences on times (stance, swing, and double support) for non-operated limb. 


\section{$7 \quad$ References}

[1] H. J. A. J. o. P.-L. C. Elftman, "Forces and energy changes in the leg during walking," vol. 125, no. 2, pp. 339-356, 1939.

[2] R. M. Alexander, "Simple models of human movement," 1995.

[3] A. Petcu, M. Georgescu, and D. Tarniţă, "Actuation systems of active orthoses used for gait rehabilitation," in Applied Mechanics and Materials, 2018, vol. 880, pp. 118-123: Trans Tech Publ. https://doi.org/10.4028/www.scientific.net/amm.880.118

[4] D. J. Geerse, B. H. Coolen, and M. J. P. o. Roerdink, "Kinematic validation of a multi-Kinect v2 instrumented 10-meter walkway for quantitative gait assessments," vol. 10, no. 10, p. e0139913, 2015. https://doi.org/10.1371/journal.pone.0139913

[5] Z. O. Abu-Faraj, G. F. Harris, P. A. Smith, S. J. W. E. o. E. Hassani, and E. Engineering, "Human gait and clinical movement analysis," pp. 1-34, 1999.

[6] J. A. DeLisa, Gait analysis in the science of rehabilitation. Diane Publishing, 1998.

[7] H. T. Alrikabi, A. H. M. Alaidi, A. S. Abdalrada, and F. T. J. I. J. o. E. T. i. L. Abed, "Analysis the Efficient Energy Prediction for 5G Wireless Communication Technologies," vol. 14, no. 08, pp. 23-37, 2019. https://doi.org/10.3991/ijet.v14i08.10485

[8] M. W. Whittle, Gait analysis: an introduction. Butterworth-Heinemann, 2014.

[9] L. Kocsis, R. M. Kiss, Z. Knoll, and M. J. F. u.-s. P. E. Jurák, "Bute's ultra-sound-based measuring technique and model for gait analysis," vol. 1, no. 6, pp. 1-13, 1999.

[10] O. H. Yahya, H. Alrikabi, I. A. J. I. J. o. O. Aljazaery, and B. Engineering, "Reducing the Data Rate in Internet of Things Applications by Using Wireless Sensor Network," vol. 16, no. 03, pp. 107-116, 2020. https://doi.org/10.3991/ijoe.v16i03.13021

[11] N. S. Alseelawi, E. K. Adnan, H. T. Hazim, H. Alrikabi, and K. Nasser, "Design and Implementation of an E-learning Platform Using N-Tier Architecture," 2020. https://doi.org/ 10.3991/ijim.v14i06.14005

[12] R. Littlewood, "The benefits and risks of the Ilizarov technique for limb re-construction [Internet]," ed: Oxford University Hospitals Limb Reconstruction, 2016.

[13] S. A. J. T. i. O. Green, "Components of the Ilizarov system," vol. 5, no. 4, pp. 1-11, 1990.

[14] K. I. Novikov, K. N. Subramanyam, S. O. Muradisinov, O. S. Novikova, E. S. J. C. O. Kolesnikova, and R. Research $\AA$, "Cosmetic lower limb lengthening by Ilizarov apparatus: what are the risks?" vol. 472, no. 11, pp. 3549-3556, 2014. https://doi.org/10.1007/s11999 $\underline{-014-3782-8}$

[15] C. C. Hasler and A. H. J. J. o. c. s. o. Krieg, "Current concepts of leg lengthening," vol. 6, no. 2, pp. 89-104, 2012.

[16] M. L. Latash, Fundamentals of motor control. Academic Press, 2012.

[17] I. A. Aljazaery, H. T. S. Alrikabi, and M. R. J. I. J. o. I. M. T. Aziz, "Combination of Hiding and Encryption for Data Security," vol. 14, no. 09, pp. 34-47, 2020. https://doi.org/10. 3991/ijim.v14i09.14173

[18] C. Kirtley, "Clinical gait analysis: theory and practice: Elsevier Health Sciences," ed: Philadelphia, 2006.

[19] R. B. Layton, T. D. Stewart, P. Harwood, and N. J. P. o. t. I. o. M. E. Messenger, Part H: Journal of Engineering in Medicine, "Biomechanical analysis of walking gait when simulating the use of an Ilizarov external fixator," vol. 232, no. 6, pp. 628-636, 2018. https:// doi.org/10.1177/0954411918776694

[20] J. Wong et al., "Gait patterns after fracture of the femoral shaft in children, managed by external fixation or early hip spica cast," vol. 24, no. 5, pp. 463-471, 2004. https://doi.org/10. $\underline{1097 / 01241398-200409000-00003}$ 
[21] J. A. Nessler, V. Gutierrez, J. Werner, and A. J. H. m. s. Punsalan, "Side by side treadmill walking reduces gait asymmetry induced by unilateral ankle weight," vol. 41, pp. 32-45, 2015. https://doi.org/10.1016/j.humov.2015.02.005

[22] S. S. Chiou, N. Turner, J. Zwiener, D. L. Weaver, and W. E. J. H. f. Haskell, "Effect of boot weight and sole flexibility on gait and physiological responses of firefighters in stepping over obstacles," vol. 54, no. 3, pp. 373-386, 2012. https://doi.org/10.1177/00187208 11433464

[23] A. S. Abdalrada et al., "A Predictive model for liver disease progression based on logistic regression algorithm," vol. 7, no. 3, pp. 1255-1264, 2019.

[24] D. Szydłak, A. Famuła, T. S. Gaździk, W. Gallert-Kopyto, J. Sołtys, and R. Plinta, "Gait analysis in children after the lengthening of the lower limb by the Ilizarov technique," in Annales Academiae Medicae Silesiensis, 2017, vol. 71, pp. 252-264. https://doi.org/10. $\underline{18794 / \mathrm{aams} / 69141}$

\section{Authors}

Omiya Mahmoud Jawad: She got her B.Sc. degree in biomedical Engineering in 2009 from the University Baghdad / Al-Khwarizmi Engineering College in Baghdad, Iraq. she is presently a student master in Biomedical Engineering, Al-Nahrain University /College of Engineering, Baghdad, Iraq. E-mail:omgh444@gmail.com

Sadiq Jaffar Hamandi: He is currently Head of Biomedical Engineering Department, College of Engineering, Al-Nahrain University, Iraq. He received his B.Sc. degree in Mechanical Engineering in 1992 from Baghdad University in Baghdad, Iraq. His M.Sc. degree in Mechanical Engineering from Al-Nahrain University /College of Engineering in 1994, and his $\mathrm{PhD}$ degree in Mechanical Engineering from Al-Nahrain University /College of Engineering in 2000. His presently research interests include Biomechanics and Biotribology, and his scientific title Assistant Professor. E-mail: sadiq_hamandi@eng.nahrainuniv.edu.iq

The number of articles in national databases 26

The number of articles in international databases 6

Dr. Safa Kadiam Al-Hussainy M.B.Ch.B. College of Medicine - Mosul university, Iraq 1991. Orthopedic and fractures specialist at Dar Al Tamriyd Private Hospital in Medical City/ Baghdad Iraq. E-mail: $\underline{\text { safaadiaa@yahoo.com }}$

Article submitted 2020-06-08. Resubmitted 2020-07-17. Final acceptance 2020-07-19. Final version published as submitted by the authors. 